\title{
Opportunities to Fail: Using Peer-review to support Assessment Literacy in Cyber Security
}

\author{
Joseph Maguire \\ University of Glasgow \\ Glasgow, Scotland, United Kingdom \\ joseph.maguire@glasgow.ac.uk
}

\author{
Rosanne English \\ University of Strathclyde \\ Glasgow, Scotland, United Kingdom \\ rosanne.english@strath.ac.uk
}

\begin{abstract}
The importance of cyber security to the global economy has only grown in recent years. Effective cyber security technical policy is an important defence against numerous threats. Consequently, it is important that computing science and software engineering graduates are able to produce effective cyber security policy. However, written assessments, such as cyber security policy, for some students may be challenging due to lack of familiarity with such assessments. The lack of familiarity or poor assessment literacy not only has the potential to produce poor results, but can led to disappointment and frustration. In this poster, the practice of integrating peer-review as part of a cyber security policy assessment task to support assessment literacy is presented. The aim is to elicit feedback from conference participants not only on the practice itself, but on addressing the challenge of assessment literacy in the context of cyber security policy.
\end{abstract}

\section{CCS CONCEPTS}

- Social and professional topics $\rightarrow$ Student assessment.

\section{KEYWORDS}

cyber security, peer-review, assessment literacy

\section{ACM Reference Format:}

Joseph Maguire and Rosanne English. 2021. Opportunities to Fail: Using Peer-review to support Assessment Literacy in Cyber Security. In 21st Koli Calling International Conference on Computing Education Research (Koli Calling '21), November 18-21, 2021, foensuu, Finland. ACM, New York, NY, USA, 2 pages. https://doi.org/10.1145/3488042.3489967

\section{INTRODUCTION}

Diverse assessments can not only stimulate and motivate students, but they also provide an opportunity to develop skills and knowledge. The concern is that diverse or novel assessments, even in senior years, may produce poor results as students have less experience with them. The challenge then becomes how to to improve assessment literacy or experience with such assessments to support students in attaining desired outcomes.

Koli Calling '21, November 18-21, 2021, foensuu, Finland

(c) 2021 Copyright held by the owner/author(s)

This is the author's version of the work. It is posted here for your personal use. Not for redistribution. The definitive Version of Record was published in 21st Koli Calling International Conference on Computing Education Research (Koli Calling '21), November 18-21, 2021, foensuu, Finland, https://doi.org/10.1145/3488042.3489967.

\section{BACKGROUND}

Assessment literacy is often considered as the process of comprehending academic judgement [1]. Specifically, that candidates performing the assessment have internalised the expected standards and criteria of it [9]. The expectation of an assessment will vary between school and university, level and between disciplines.

One assumption in assessment literacy is that individuals attempting a written assessment in their senior year of study will have considerable experience to draw upon [3]. The concern is that some computing science students may not have sufficient experience in written assessments, even in their senior years. The situation is not surprising as such students may have spent several years expressing themselves through programming rather than essay writing. Thus the outcome for some strong capable students may be frustration and disappointment due to a lack of awareness around the expectations of the assessment [5].

Consequently, the challenge becomes how to provide opportunities for students to fail so that they can refine their assessment literacy. There are potentially many different options, but peer-review integrated into an assessment, may provide an early opportunity for students to receive relevant feedback [14]. There are several examples of peer-review with computing science students.

Petersen and Zingaro utilised peer-review to engage students in meeting the expectations of design and style of source code [8]. They argue that while the process is invaluable in ensuring students appreciate the important aspects of high-quality source code, students must be supported to produce valuable feedback. Similarly, Ross states that inclusion of peer-review into assessments can be valuable, but students must be supported to be of any benefit [11]. However, high-quality feedback is only valuable if students actually consider and act upon it. $\mathrm{Li}$ et al. requested computing science students to peer-review projects prior to submission [4]. The expectation was that students would refine their work inline with the feedback they received. However, Li et al. reported that while students reported that the feedback was valuable and appreciated, the quality of work did not improve. Nevertheless, Nicol et al. argues that requesting students to develop and create feedback for peers leads to self-critique of their own efforts [6].

Consequently, while peer-review can be valuable, the design of the process should ensure that (1) students are supported in the creation of reviews and are (2) prompted to actually plan for action.

\section{THE LEARNING DESIGN}

The assessment required teams of 3 to 5 students to produce appropriate cyber security policy for a given context. Teams were expected to produce a six-page report that contained investigation into relevant threats and vulnerabilities, thorough risk assessment, 
appropriate policy as well as an evaluation plan and identification of validation metrics.

The assessed exercise specification provided a detailed marking scheme. The marking scheme was weighted heavily to specific aspects of the assessment with a small reward for imperative skills that are often under appreciated by some students, such as quality of writing and team performance. Teams had 10 weeks to produce the report, but are required to provide a draft report for peer-review in the first 5 weeks.

The draft report did not need to be complete, but it had to represent a reasonable attempt. Teams were advised to focus on areas they were unsure of when producing drafts, so as to ensure valuable feedback. The draft report was not assessed but had a weight of 0 or 1 , where 1 represents a reasonable attempt. The weight is multiplied by the final grade, if teams do not make a reasonable attempt they fail the assignment. Teams were required to upload the draft report to a peer-review system.

Teams were required to review 3 draft reports from other teams as part of the assessment. Teams were required to complete a marking rubric and one-page review for each draft. The marking rubric is effectively a questionnaire with open-text responses as well as Likert scales that probe important aspects of the assessment. Teams were also given guidance on how to produce a one-page review. Teams were assessed on each completed marking rubric and review.

The assumption was that teams would consider the expectations and quality of the assessment by reviewing several drafts with the rubric and through production of their own reviews. The process afforded teams the ability to self-regulate and begin to critique and judge their own drafts using the same process, before receiving any reviews from other teams.

Teams were given 2 weeks to complete reviews. After the review period each team would receive 3 reviews of their work. Teams were required to produce a plan for action for each review. The plan for action is designed for teams to consider the feedback from other teams and articulate the action or inaction they will take in revising the draft. Teams are expected to produce a plan of action for each review and performance contributes to the final grade of the team.

\section{CHALLENGES}

After delivering the learning design for 4 years, there are apparent benefits to the approach. The primary benefit is that students appear notably less anxious and confused about the expectations of the assessment. In terms of significant performance improvement, this would have to be investigated thoroughly and is beyond the scope of this short paper.

The challenge in delivering the learning design is that it can be expensive, if not properly supported with an appropriate system, such as Aropa or Moodle Workshop. The expense for the learning design is primarily associated with considering and marking peer-review components to motivate students to complete them satisfactory. Similarly, Gehringer et al. experiences of peer-review on programming courses is that while its valuable, the process is time expensive in terms of administration and coordination [2]. However, Gehringer et al. argues such pressures do reduce as instructors gain more experience with the process [2].
There is also the challenge of poor quality or inconsiderate reviews [10]. The use of a marking rubric in the current learning design is an approach to ensure a consistent and minimum level of quality for each review. The concern is that while some students consider and craft valuable reviews, others may perceive the process as 'form-filling'. Similarly, Nortcliffe argued peer-review generated a lot of value and noise from students when utilised as part of website design course [7]. Norfolk argues that such noise could potentially be addressed with training. However, Schroter et al. demonstrated that while peer-review training can have an impact in the short-term to review quality, it has no significant impact in the long-term [13]. Nevertheless, ensuring a valuable and constructive experience is important as students may be unwilling to participant in subsequent peer-review processes after a bad experience [12].

\section{CONCLUSION}

Peer-review is an effective and valuable tool in providing feedback cycles for students to refine their assessment literacy. The approach can potentially reduce student frustration in making mistakes through simply not appreciating assessment expectations and standards. An approach that could be valuable for less familiar exercises, such as written assessment, for senior year computing science students. However, lecturers must be aware that any design may be expensive to initially explore and students must be sufficiently supported to avoid a process that generates a long lasting negative experience.

\section{REFERENCES}

[1] Joint Information Systems Committee et al. 2015. Transforming assessment and feedback with technology. JISC Innovation Group.

[2] Edward F Gehringer, Donald D Chinn, Manuel A Pérez-Quiñones, and Mark A Ardis. 2005. Using peer review in teaching computing. In Proceedings of the 36th SIGCSE technical symposium on Computer science education. 321-322.

[3] Dai Hounsell. 1997. Contrasting conceptions of essay-writing. The experience of learning 2 (1997), 106-125.

[4] Lan Li, Xiongyi Liu, and Allen L Steckelberg. 2010. Assessor or assessee: How student learning improves by giving and receiving peer feedback. British fournal of Educational Technology 41, 3 (2010), 525-536.

[5] Michael P McEwan. 2016. The essay as a lens on transition to university: student and staff perceptions of essay writing. International fournal of Teaching and Learning in Higher Education (2016).

[6] David Nicol, Avril Thomson, and Caroline Breslin. 2014. Rethinking feedback practices in higher education: a peer review perspective. Assessment \& Evaluation in Higher Education 39, 1 (2014), 102-122.

[7] Anne Nortcliffe. 2012. Can students assess themselves and their peers?: a five year study. Student Engagement and Experience fournal 1, 2 (2012).

[8] Andrew Petersen and Daniel Zingaro. 2018. Code Reviews in Large, First-year Courses. In Proceedings of the 23rd Annual ACM Conference on Innovation and Technology in Computer Science Education (ITiCSE 2018). ACM, New York, NY, USA, 354-355. https://doi.org/10.1145/3197091.3205832

[9] Margaret Price, Chris Rust, Berry O'Donovan, Karen Handley, and Rebecca Bryant. 2012. Assessment literacy: The foundation for improving student learning. Oxford Centre for Staff and Learning Development, Oxford Brookes University.

[10] Arnold Rosenbloom. 2017. Spreading trust in an online peer assessment application. In Proceedings of the 22nd Western Canadian Conference on Computing Education. 1-1.

[11] John A Ross. 2006. The reliability, validity, and utility of self-assessment. (2006).

[12] Christopher Rushton et al. 1993. Peer assessment in a collaborative hypermedia environment: A case study. Fournal of Computer-Based Instruction 20, 3 (1993), $75-80$.

[13] Sara Schroter, Nick Black, Stephen Evans, James Carpenter, Fiona Godlee, and Richard Smith. 2004. Effects of training on quality of peer review: randomised controlled trial. Bmj 328, 7441 (2004), 673.

[14] Anne Venables and Raymond Summit. 2003. Enhancing scientific essay writing using peer assessment. Innovations in education and teaching international 40, 3 (2003), 281-290. 